TABLE 1. Patient characteristics and outcomes

\begin{tabular}{|c|c|c|c|c|c|c|c|c|}
\hline Patient & Diagnosis & $\begin{array}{c}\text { Year of } \\
\text { operation }\end{array}$ & Age (y) & BSA $(\mathbf{m} 2)$ & Graft size $(\mathbf{m m})$ & Follow-up (y) & Late AR & Reoperation \\
\hline $1 *$ & Marfan syndrome & 2002 & 14.5 & 1.85 & 30 & 8.8 & None & Bentall procedure \\
\hline $2 \dagger$ & TOF & 2003 & 15.6 & 1.75 & 30 & 5.7 & Mild & False aneurysm repair \\
\hline $3 \ddagger$ & Taussig-Bing + CoA & 2006 & 12.8 & 1.44 & 26 & 4.3 & None & None \\
\hline 4 & Marfan syndrome & 2006 & 16 & 1.76 & 28 & 4.7 & None & None \\
\hline $5 \S$ & Loeys-Dietz syndrome & 2006 & 16.2 & 1.63 & 28 & 4.6 & None & None \\
\hline 6 & Takayasu arteritis & 2007 & 12.6 & 1.28 & 26 & 3.8 & None & None \\
\hline $7 \|$ & Tricuspid atresia, TGA, IAA, VSD & 2008 & 15 & 1.51 & 26 & 3.2 & Mild & None \\
\hline 8 & Marfan syndrome & 2009 & 10.1 & 1.58 & 26 & 1.9 & Mild & None \\
\hline 99 & TOF & 2010 & 17.4 & 1.96 & 30 & 2 & None & None \\
\hline 10 & Loeys-Dietz syndrome & 2011 & 7.4 & 0.73 & 24 & 0.1 & None & Aortic homograft \\
\hline
\end{tabular}

$B S A$, Body surface area; $A R$, aortic regurgitation; $T O F$, tetralogy of Fallot; CoA, coarctation of aorta; TGA, transposition of the great arteries; IAA, interrupted aortic arch; VSD, ventricular septal defect. *Previous mitral valve repair in 2001. †Previous TOF repair in 1988. †Previous atrial septal defect closure in 1997. §Previous CoA repair in 1993, arterial switch operation and VSD closure in 1994, and relief of subaortic stenosis in 1998. ||Previous IAA repair, atrial septectomy, and pulmonary artery banding in 1993, arterial switch operation in 1993, bidirectional cavopulmonary shunt in 1995, and Fontan procedure in 2000. \Previous TOF repair in 1992.

rate of $42.9 \%(6 / 14)$ that included $5(45.4 \%, 5 / 11)$ aortic valve reoperations in the remodeling group and $1(33 \%$, $1 / 3$ ) Bentall procedure in the reimplantation group.

At the present time, valve-sparing aortic root replacement with reimplantation of the native valve into a graft with sinuses seems superior to aortic root replacement with a homograft or a composite graft in children. ${ }^{1-3}$ Further long-term studies will be required to confirm or refute this notion.

\section{CONCLUSIONS}

Valve-sparing aortic root replacement in children provides good intermediate outcomes. Aortic valve reimplantation into a graft with sinuses is the technique of choice.

\section{References}

1. Patel ND, Arnaoutakis GJ, George TJ, Allen JG, Alejo DE, Dietz HC, et al. Valvesparing aortic root replacement in children: intermediate-term results. Interact Cardiovasc Thorac Surg. 2011;12:415-9.

2. Roubertie F, Ben Ali W, Raisky O, Tamisier D, Sidi D, Vouhe PR. Aortic roo replacement in children: a word of caution about valve-sparing procedures. Eur J Cardiothorac Surg. 2009;35:136-40.

3. Vricella LA, Williams JA, Ravekes WJ, Holmes KW, Dietz HC, Gott VL, et al. Early experience with valve-sparing aortic root replacement in children. Ann Thorac Surg. 2005;80:1622-6.

4. Konstantinov IE, Fricke TA, d'Udekem Y, Robertson T. Aortic dissection and rupture in adolescents after tetralogy of Fallot repair. J Thorac Cardiovasc Surg. 2010;140:e71-3.

5. Gautier M, Detaint D, Fermanian C, Aegerter P, Delorme G, Arnoult F, et al Nomograms for aortic root diameters in children using two-dimensional echocardiography. Am J Cardiol. 2010;105:888-94.

\title{
Direct visualization of the aortic cusp from the left ventricle during aortic root reimplantation
}

\author{
Yutaka Okita, PhD, MD, Takanori Oka, MD, Shunsuke Miyahara, MD, and Kenji Okada, MD, PhD, \\ Hyogo, Japan
}

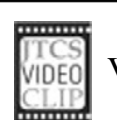

Video clip is available online.

From the Department of Cardiovascular Surgery, Kobe University, Hyogo, Japan. Disclosures: Authors have nothing to disclose with regard to commercial support. Received for publication March 19, 2012; revisions received April 2, 2012; accepted for publication May 7, 2012.

Address for reprints: Yutaka Okita, PhD, MD, Department of Cardiovascular Surgery,

Kobe University, 5-7-1 Kusunoki-cho, Chuo-ku, Kobe Hyogo 650-0017, Japan

(E-mail: yokita@med.kobe-u.ac.jp).

J Thorac Cardiovasc Surg 2012;144:981-2

$0022-5223 / \$ 36.00$

Copyright $(92012$ by The American Association for Thoracic Surgery

http://dx.doi.org/10.1016/j.jtcvs.2012.05.002
The patient was 52-year-old man who was diagnosed with annuloaortic ectasia and aortic valve regurgitation. $\mathrm{He}$ was asymptomatic; however, the transthoracic and transesophageal echocardiograms revealed that he had severe aortic regurgitation (regurgitation volume, $73 \mathrm{~mL}$; regurgitant fraction, $43 \%$; left ventricular diastolic dimension, 70 $\mathrm{mm}$; systolic dimension, $54 \mathrm{~mm}$, and ejection fraction, $45 \%$ ). The aortic valve was tricuspid, and the diameter of the ventricular aortic junction, sinus of Valsalva, and sinotubular junction was 26,45 , and $45 \mathrm{~mm}$, respectively.

He underwent aortic root replacement with a valvesparing technique. The aortic root was replaced with a 28$\mathrm{mm}$ Valsalva graft (Terumo Medical, Somerset, NJ) with 12 reinforced 3-0 polyester mattress sutures in the first 
row and continuous 5-0 polypropylene sutures in the second row. The cusp competency was assessed by direct visualization using the videoscope $(3.3 \mathrm{~mm}$ in diameter; Olympus, Tokyo, Japan), which was inserted from the left upper pulmonary vein through the mitral valve and into the left ventricle (Figure 1). The left ventricular venting was continued. The tip of the scope is flexible and was set toward the aortic cusp. The aortic root was pressurized using cardioplegic solution, and the prolapse of the right coronary cusp was clearly demonstrated (Video 1). The free margin of the right coronary cusp was plicated at the Arantius node by $7 \mathrm{~mm}$ using 6-0 polypropylene suture. The competency of the aortic cusp was confirmed by the videoscope (Video 2). Next, the coronary and distal anastomoses were done by 5-0 polypropylene. The cardiopulmonary bypass was weaned, and the transesophageal echocardiogram disclosed normal integrity of the aortic root with no aortic regurgitation.

The method for assessing aortic regurgitation after aortic valve repair during cardiac arrest has been investigated. Usually "eye-ball" testing by surgeons is used. Kunihara and colleagues ${ }^{1}$ introduced some scientific measurements of the cusp morphology using a specialized caliper. The water injection test into the open aortic root is not reliable, and an assessment using transesophageal echocardiography necessitates a coronary anastomosis, distal aortic anastomosis, and aortic declamping. Direct visualization of the aortic cusps after aortic valve repair or aortic root replacement using the valve-sparing technique was reported by Ito and colleagues ${ }^{2}$; however, they observed the aortic cusps from the aortotomy. No reports have been published

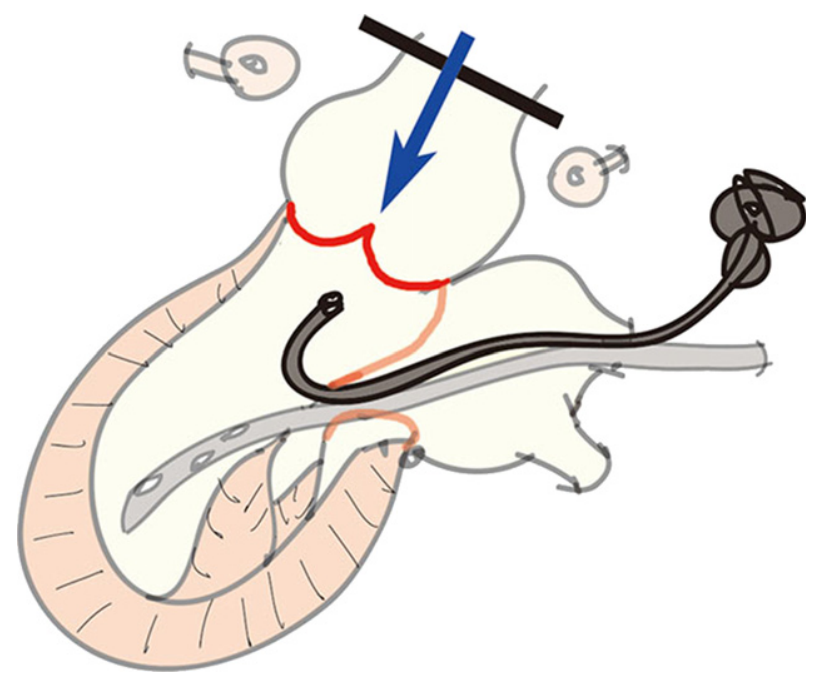

FIGURE 1. The videoscope is inserted from the left upper pulmonary vein through the mitral valve and into the left ventricle.

describing the assessment of the aortic cusps from the left ventricle. The greatest advantage of this method is that direct and instantaneous visualization of valve leakage is possible. The surgeon can then determine the strategy for valve repair according to the video images.

\section{References}

1. Kunihara T, Aicher D, Rodionycheva S, et al. Preoperative aortic root geometry and postoperative cusp configuration primarily determine long-term outcome after valve-preserving aortic root repair. J Thorac Cardiovasc Surg. 2012;143:1389-95.

2. Itoh T, Ohtsubo S, Furukawa K, Norita H. Aortic root endoscopy in valve-sparing operations. J Thorac Cardiovasc Surg. 1997;114:141.

\section{Perfusion and repair technique in acute aortic dissection with cerebral malperfusion and damage of the innominate artery}

\author{
Extension of the acute aortic dissection in supra-aortic \\ branches can cause cerebral malperfusion and present \\ a surgical challenge. The innominate artery is, as a first branch \\ From the Departments of Cardiovascular Surgery ${ }^{\mathrm{a}}$ and Radiology, ${ }^{\mathrm{b}}$ Cardiovascular \\ Clinic Bad Neustadt, Bad Neustadt, Germany. \\ Disclosures: Dr Urbanski has a financial relationship with MAQUET Cardiovascular, \\ Inc (La Ciotat, France). Dr Wagner has nothing to disclose with regard to commer- \\ cial support. \\ Received for publication Jan 31, 2012; revisions received April 18, 2012; accepted for \\ publication May 16, 2012; available ahead of print June 18, 2012. \\ Address for reprints: Paul P. Urbanski, MD, PhD, Herz-und Gefaess-Klinik, Salzbur- \\ ger Leite 1, 97616 Bad Neustadt, Germany (E-mail: p.urbanski@ @erzchirurgie.de). \\ J Thorac Cardiovasc Surg 2012;144:982-4 \\ $0022-5223 / \$ 36.00$ \\ Copyright (C) 2012 by The American Association for Thoracic Surgery \\ http://dx.doi.org/10.1016/j.jtcvs.2012.05.042
}

Paul P. Urbanski, MD, PhD, ${ }^{a}$ and Matthias Wagner, MD, ${ }^{\mathrm{b}}$ Bad Neustadt, Germany of the aortic arch, most frequently involved in the dissection, and the short distance to its bifurcation can occasionally cause complex pathology, which can lead to real anastomosis problems during arch repair. In such cases, cannulation of the right carotid artery (RCA) is especially advantageous because it ensures sufficient cerebral perfusion during surgery, and, if the extensive damage of the innominate artery makes direct anastomosis with a vascular prosthesis challenging or even unsuitable, it allows use of the cannulation side-graft for the use of an aorta-carotid bypass.

\section{CLINICAL SUMMARY}

To ensure sufficient cerebral and global perfusion in patients with cerebral malperfusion caused through 